\title{
AVANCES SOBRE LA EQUIDAD Y LA PARIDAD DE GÉNERO EN MÉXICO
}

"La primera igualdad, es la equidad".

Victor Hugo

\author{
Lizbeth Gabriela Corral Limas ${ }^{1}$ \\ Alma Yolanda Morales Corral ${ }^{2}$ \\ Verónica Ofelia Lozano Sandoval ${ }^{3}$
}

\section{Resumen}

El presente artículo analiza los avances sobre la equidad y la paridad de género en México a través de las reformas que han ido efectuándose a la legislación y en los organismos internacionales, observando el impacto de las cuotas de género, y el efecto que estos factores han tenido en la participación política de las mujeres, que históricamente se ha presentado con desventaja con respeto a los hombres. Se analizarán los resultados de la elección federal 2018 y las posiciones ocupadas por mujeres derivadas de dicho ejercicio democrático, que, como efecto de las cuotas de género, han cambiado el rumbo de la representación tanto en la Cámara de diputados como en el Senado de la República. Los resultados de la investigación permiten observar, que, en México, se ha podido ver una evolución durante casi 25 años sobre este tema, para pasar de tener hasta un $70 \%$ de legisladores del mismo género en 1996, a contar, como resultado de la obligatoriedad de la paridad de género en la elección de 2018 , con un $49.2 \%$ de mujeres en el Senado de la República y un $48.2 \%$ en la Cámara de Diputados, consideradas al día de hoy como cifras históricas.

Palabras clave: Equidad de género, mujeres, política, paridad de género, México.

\footnotetext{
${ }^{1}$ Doctora en Administración, Docente hora clase en la Facultad de Ciencias Políticas y Sociales de la Universidad Autónoma de Chihuahua, en Ciudad Juárez, Chih. Universidad Autónoma de Chihuahua - México. ORCID iD: https://orcid.org/0000-0001-8811-750X Lattes: http://lattes.cnpq.br/9136713565471716 E-mail: lizzyc12001@yahoo.com.mx

2 Maestra en Administración, Docente de tiempo completo en la Facultad de Ciencias Políticas de la Universidad Autónoma de Chihuahua, en Ciudad Juárez, Chih. Universidad Autónoma de Chihuahua - Méxica. ORCID iD: https://orcid.org/0000-0002-3867-7514 Lattes: http://lattes.cnpq.br/8822803072576813 E-mail: almayolanda.morales@yahoo.com.mx

3 Maestra en Administración, Docente de tiempo completo en la Facultad de Ciencias Políticas de la Universidad Autónoma de Chihuahua, en Ciudad Juárez, Chih. Universidad Autónoma de Chihuahua - México. ORCID iD: https://orcid.org/0000-0002-8250-8697 Lattes: http://lattes.cnpq.br/5009556854209824 E-mail: vlozano@uach.mx
} 


\section{Introducción}

Si bien en términos jurídicos, mujeres y hombres gozan de iguales derechos para participar en la vida política del país, esta igualdad de jure no ha logrado traducirse en la presencia y participación igualitaria de unas y otros en el ámbito público y la representación política. Por el contrario, estos espacios todavía suelen leerse y comprenderse en códigos masculinos, lo que implica que los cargos públicos, ejecutivos, de adopción de decisiones políticas y todos aquellos que implican el ejercicio del poder público, sean ocupados mayoritariamente por hombres y, por ende, se margina a las mujeres de los procesos estratégicos y definitorios de la agenda pública, así como de las deliberaciones sobre asuntos de vital importancia para el interés colectivo. Esta situación de franca discriminación hacia las mujeres ha motivado el reconocimiento internacional y nacional acerca de la necesidad de poner en marcha medidas afirmativas en beneficio de las mujeres (Medina, 2010).

En México, analizando casi 25 años la evolución del tema, encontramos, por ejemplo, que ha sido una práctica común, que, dentro de las legislaturas, a las mujeres se les integre a comisiones de temas que no son prioritarios y han sido muy pocas las que presiden comisiones, y cuando lo hacen son destinadas a comisiones consideradas "tradicionalmente femeninas".

Fue en 1996, que se estableció que sólo se podían tener hasta un 70\% de legisladores del mismo género.

En 2008, destacó la implementación del sistema de cuotas de género, una acción afirmativa que obligó en el ámbito federal en México, a no presentar más de $60 \%$ de candidaturas de un mismo sexo en los comicios para el Congreso Federal. Esta medida fue aprobada como parte de las reformas aplicadas al nuevo Código Federal de Instituciones y Procedimientos Electorales (COFIPE), publicado en el Diario Oficial de la Federación (DOF) el 14 de enero de 2008. De manera que fue apenas en las elecciones del 2009 cuando se instrumentaron por primera vez estas cuotas de género, anteriormente venía aplicándose la ecuación 70/30 en las candidaturas para las elecciones legislativas federales. Dichas cuotas, si bien han sido importantes en el propósito de aumentar la presencia de las mujeres en los espacios de representación política, al mismo tiempo, han resultado ser insuficientes y limitadas si se considera que no se logró contar siquiera en el Congreso Federal con una "masa crítica" de mujeres, esto es, una presencia mínima suficiente capaz de incidir de manera efectiva en la definición de la agenda pública y en la 
adopción de decisiones políticas, como primer paso hacia una distribución equitativa y equilibrada del ejercicio del poder entre mujeres y hombres (Medina, 2010).

Posteriormente, en el proceso electoral de 2011-2012, la Sala Superior del Tribunal Electoral del Poder Judicial de la Federación, impuso a los partidos políticos y coaliciones la obligación de nombrar como mínimo 120 fórmulas de candidatos propietarios y suplentes de un mismo sexo para la Cámara de Diputados y 26 para el Senado, respectivamente. Además, el IFE (Instituto Federal Electoral) emitió un acuerdo para establecer los criterios a los que los partidos políticos debían de apegarse para cumplir con el mandato del tribunal, teniéndose como resultado, que el porcentaje de integración femenina en el Congreso Federal alcanzara cerca del 35\%; es decir, 185 mujeres diputadas y 42 senadoras, o sea, que 227 diputaciones federales y senadurías fueran ocupadas por mujeres, cuestión que fue un hecho histórico en su momento. Por último, ya en las elecciones de 2018, con la paridad de género estipulada en la ley, se tuvo como resultado que en la Legislatura LXIV se pudiera contar con un $49 \%$ de mujeres en el Senado y un $48 \%$ en la Cámara de Diputados, consideradas cifras históricas sobre el impacto y alcance de la paridad. Resultan entonces trascendentales los cambios a la ley que han permitido dichos avances (Cámara de Diputados y Senado de la República, s.f.).

\section{Antecedentes}

La equidad de género se ha definido como: "Principio que, conscientes de la desigualdad existente entre mujeres y hombres, permite el acceso con justicia e igualdad de condiciones al uso, control, aprovechamiento y beneficio de los bienes, servicios, oportunidades y recompensas de la sociedad; lo anterior con el fin de lograr la participación de las mujeres en la toma de decisiones en todos los ámbitos de la vida social, económica, política, cultural y familiar" (Solorio, 2014).

Para la FIDA (Investing in Rural People), por equidad de género "se entiende el trato imparcial de mujeres y hombres, según sus necesidades respectivas, ya sea con un trato equitativo o con uno diferenciado pero que se considera equivalente por lo que se refiere a los derechos, los beneficios, las obligaciones y las posibilidades. En el ámbito del desarrollo, el objetivo de lograr la equidad de género, a menudo exige la incorporación de medidas específicas para compensar las desventajas históricas y sociales que arrastran las mujeres" (Solorio, 2014). 
El concepto de equidad de género surge en la necesidad de ir más allá de un discurso centrado en la diferencia, en la necesidad de construir un nuevo debate sobre la igualdad y la diferencia, orientado a las múltiples diferencias que se intersectan, siendo necesario vincular la problemática de la diferencia cultural con la problemática de la igualdad social. "La equidad de género como noción comprehensiva, involucra la tensión entre la igualdad y la diferencia, así como la complementariedad de la justicia social con la justicia cultural. Es decir, la justicia de género tiene connotaciones culturales y económicas, aspectos que requieren políticas de reconocimiento de las diferencias y aspectos que tienen que ver con políticas de redistribución, en el sentido de igual participación de los beneficios entre hombres y mujeres. Esto, en el marco de una concepción ampliada de la equidad, ligada a la consideración de todo tipo de desigualdades y diferencias, no sólo a las diferencias de género, sino incorporando las diferencias de clase, etnia, 'raza', generación, sexualidad, región, ubicación en el orden mundial, etc. (Mora, 2006).

La equidad de género, al igual que la equidad concebida de manera general, busca eliminar por un lado la desigualdad social y por otro el irrespeto de la diferencia”. La desigualdad social en relación al género refiere a la reclusión de las mujeres al espacio doméstico y a su marginación del espacio público, a la injusta distribución de los bienes sociales esenciales, tales como el ingreso, el empleo, la propiedad, la salud, la educación, la integridad física y la seguridad personal. Incluye la desigual distribución de los recursos, la desigual carga de trabajo, la desigual compensación económica recibida por el mismo trabajo que desarrolla un varón, entre otros. El irrespeto a la diferencia, en el ámbito del género, apunta al no respeto de las mujeres por ser mujeres. La diferencia de lo femenino es lo no respetado. La negación de su autonomía, el placer sexual, la no valoración de las cualidades, actividades y espacios ocupados por las mujeres. La falta de reconocimiento de sus formas de percibir el mundo y su perspectiva distinta (Mora, 2006).

La equidad de género está vinculada con la equidad social en la medida en que las desigualdades de género, en las distintas sociedades, se encuentran articuladas con otras desigualdades de clase, 'raza', etnicidad, edad, etc. De manera que hay un nexo innegable y una retroalimentación entre las inequidades de género y otro tipo de desigualdades sociales (Mora, 2006). 
En relación a cómo se interrelacionan las desigualdades de género con otras desigualdades, según Nancy Fraser, la equidad de género incluye principios de igualdad, aspectos redistributivos, cruces con otros tipos de equidad social, diferencias dignas de reconocimiento y valoración. Los principios centrales son el principio de antipobreza, el principio de anti explotación, el principio de igualdad en el ingreso, el principio de igualdad de tiempo libre, principio de igualdad de respeto, principio de anti marginación y el principio de anti androcentrismo (Fraser, 1997).

El concepto de paridad es reciente y su mayor impulso parece coincidir con la realización de la Conferencia de Atenas en 1992, en la cual se definió la paridad como "la total integración, en pie de igualdad de las mujeres, en las sociedades democráticas, utilizando para ello las estrategias multidisciplinarias que sean necesarias" (Cámara de Diputados).

La paridad de género busca garantizar la participación equilibrada de mujeres y hombres en la toma de decisiones, teniendo como marco la promoción de la igualdad de oportunidades. La necesidad de su implementación se basa en que la limitada participación de las mujeres en los niveles decisorios obstaculiza el desarrollo humano, al no incorporarse las demandas e intereses de las mujeres en todos los aspectos de la vida política, social, cultural y económica de la sociedad (Cámara de Diputados).

Las cuotas de género, más conocidas como cuotas de participación por sexo o cuotas de participación de mujeres, son una forma de acción positiva cuyo objetivo es garantizar la efectiva integración de mujeres en cargos electivos de decisión de los partidos políticos y del Estado. Es una medida de carácter compulsivo, que obliga a incorporar mujeres en listas de candidaturas o en listas de resultados electorales, y transitorio, puesto que supone una vigencia sujeta a la superación de los obstáculos que impiden una adecuada representación de mujeres en los espacios de poder y representación política (Fernández, 2011).

La idea central de los sistemas de cuotas es seleccionar mujeres para puestos en las instituciones de gobierno y garantizar que éstas no queden marginadas de la vida política o tengan una presencia meramente decorativa. Las cuotas se pueden aplicar como una medida temporal, es decir, hasta que las barreras que impiden el acceso de las mujeres a la política sean eliminadas (Fernández, 2011). 
Hay toda una polémica a favor y en contra de esta medida discriminatoria, correctora de una escasez, temporal y justificada en cada contexto social y en nuestros días. Si bien es cierto que se trata de discriminación en positivo, es discriminación, al fin y al cabo, y el debate se centra en la justicia, equidad y carácter democrático de dicha medida. Pero, por otro lado, otro tanto podríamos decir sobre la no presencia o reducida participación de las mujeres en los espacios de poder político. Por todo lo cual, llegar a una conclusión sobre el tema es poco menos que imposible, y sólo desde una posición político ideológica o jurídica se podría arribar (Fernández, 2011).

A favor de las cuotas de puede argumentar grosso modo que:

- Evitan la discriminación y fomentan la igualdad de oportunidades entre hombres y mujeres.

- Es un derecho político de las mujeres la representación formal tendiente a la equidad.

- Es una necesidad que la experiencia de las mujeres también esté en la vida pública.

- Visibilizan la discriminación de género y mantienen el tema en la agenda política del país.

- Es parte de la ampliación y profundización, así como la calidad de la democracia misma (Fernández, 2011).

Ha sido importante y necesaria pues, la incorporación de los conceptos de equidad, paridad y cuotas de género para lograr lo alcanzado hasta la más reciente legislatura en ambas Cámaras, una representatividad real, con números nunca antes vistos y, sobre todo, con la intención por parte de todos los actores de la política en México, de que estos esfuerzos continúen, dando cabida, cada vez más, al lenguaje femenino dentro de las esferas del poder político.

\section{La Igualdad y Equidad de Género en los Organismos Internacionales}

Para la Organización de las Naciones Unidas para la Educación, la Ciencia y la Cultura, (UNESCO) la igualdad de género significa iguales derechos, beneficios, obligaciones, oportunidades, e igual valoración a pesar de diferencias y roles distintos. En este marco, la igualdad de género es la meta final y estado ideal. Mientras que la equidad de género implica 
imparcialidad, y por tanto alude a un principio de justicia para corregir la ley. La equidad de género es un medio, un proceso, los programas dirigidos a lograr la igualdad (UNESCO, s.f.)

Para la CEPAL, Comisión Económica para América Latina y El Caribe, Equidad de Género está asociada a la consideración de la diversidad de experiencias de las mujeres y de los distintos grupos sociales, en términos de inserción en la estructura social, pertenencia étnica, diferencias etarias y condiciones de vida. Es prioritario el vínculo indisoluble entre la equidad social y de género con el respeto y ejercicio de los derechos humanos de mujeres y hombres. Avanzar hacia la Igualdad de Género requiere de la redistribución de la riqueza, el poder y el tiempo (CEPAL, 2004).

Para la Organización mundial de la salud, OMS, la Igualdad de Género es la ausencia de discriminación basada en el sexo de la persona en materia de oportunidades, asignación de recursos y beneficios o acceso a los servicios, mientras la Equidad de Género: refiere a la imparcialidad y la justicia en la distribución de beneficios y responsabilidades entre hombres mujeres. El concepto reconoce que hombre y mujer tienen distintas necesidades y gozan de distinto poder, y que esas diferencias deben determinarse y abordarse con miras a corregir los desequilibrios entre los sexos (OMS, 2002).

La Convención sobre la eliminación de todas las formas de discriminación contra la mujer (CEDAW, por sus siglas en inglés), es la carta internacional de los derechos de la mujer y provee un marco obligatorio de cumplimiento para los países que la han ratificado para lograr la igualdad de género y el empoderamiento de las mujeres y las niñas. La CEDAW fue adoptada en forma unánime por la Asamblea General de las Naciones Unidas el 18 de diciembre de 1979 y entró en vigor en 1981. La CEDAW es el segundo instrumento internacional más ratificado por los Estados Miembro de la ONU, -el primero es la Convención sobre los Derechos de la Niñez-; y a la fecha, ha sido ratificada por 186 países, lo que le otorga un poderoso mandato internacional. El espíritu de la Convención tiene su origen en los objetivos de las Naciones Unidas: reafirmar los derechos humanos fundamentales, la dignidad y el valor de la persona humana y la igualdad de derechos de hombres y mujeres. La Convención define el significado de la igualdad e indica cómo lograrla. En este sentido, la Convención establece no sólo una declaración internacional de derechos para la mujer, sino también un programa de acción para que los Estados Parte garanticen el goce de esos derechos. La CEDAW convoca a los gobiernos a legislar para hacer realidad la igualdad de género y también señala que los gobiernos son responsables no sólo de adoptar leyes 
adecuadas, sino de velar por sus efectos y porque no se discrimine a las mujeres. De igual forma, la CEDAW promueve el uso de medidas especiales transitorias, como las cuotas, para aumentar la participación de la mujer en todos los niveles de la toma de decisiones. En última instancia, la CEDAW exhorta a los Estados a tomar "todas las medidas necesarias" para cambiar las actitudes sociales y culturales y eliminar los prejuicios y las prácticas tradicionales basadas en estereotipos o ideas que discriminan a las mujeres (ONU, s.f.).

A pesar de que 186 países han ratificado la CEDAW, y haberse logrado considerables avances a nivel nacional en las Constituciones y Leyes a fin de respetar la igualdad entre mujeres y hombres; todavía persisten marcos y prácticas discriminatorias, por ejemplo, en relación con la tierra, los derechos a la propiedad y las prestaciones en el empleo. Los obstáculos en el acceso a la justicia, especialmente para las mujeres y niñas más pobres, siguen menoscabando las iniciativas orientadas a eliminar la discriminación por motivos de género. Por lo anterior, en julio de 2010, la Asamblea General de las Naciones Unidas creó ONU Mujeres, la Entidad de las Naciones Unidas para la Igualdad de Género y el Empoderamiento de las Mujeres. Como defensora mundial de mujeres y niñas, la misión de ONU Mujeres gira en torno a su función de entidad rectora y coordinadora de los esfuerzos del sistema de las Naciones Unidas por asegurar que los compromisos contraídos en relación con la igualdad de género y la incorporación de la perspectiva de género, se traduzcan en medidas concretas en los países; por ello, el mandato de ONU Mujeres se rige por la CEDAW y también por otros instrumentos internacionales, tales como la Plataforma de Acción de Beijing, la Declaración del Milenio, las resoluciones pertinentes de la Asamblea General, del Consejo Económico y Social y la Comisión de la Condición Jurídica y Social de la Mujer y demás instrumentos y normas aplicables de las Naciones Unidas. Por otro lado, es importante mencionar, que la CEDAW es un instrumento internacional dinámico que se adapta a la evolución del derecho internacional. Desde su primer período de sesiones en 1982, el Comité para la Eliminación de la Discriminación contra la Mujer y otros actores nacionales e internacionales han contribuido a aclarar e interpretar el contenido sustantivo de los artículos de la Convención, la naturaleza específica de la discriminación contra la mujer y los diversos instrumentos para hacerle frente. En este sentido, el Comité de la CEDAW puede hacer sugerencias y recomendaciones1 de carácter general basadas en el examen de los informes y de los datos transmitidos por los Estados Partes (ONU, s.f.). 
Con la finalidad de que los derechos de la mujer se traduzcan en progresos sustantivos en sus vidas, y para que la igualdad de género sea una realidad; ONU Mujeres presenta esta edición de la CEDAW con las dos últimas recomendaciones del Comité de la Convención: Recomendación General No. 27 sobre las mujeres de edad y la protección de sus derechos humanos; y Recomendación General No. 28 sobre el artículo 2 de la Convención referente a las obligaciones jurídicas de los Estados Parte para respetar, proteger y hacer cumplir el derecho de las mujeres a la no discriminación y al goce de la igualdad. Motivamos a los hombres y especialmente a las mujeres a que conozcan esta "carta de los derechos de las mujeres", con el fin de que puedan participar plenamente en la adopción de decisiones públicas a todos los niveles y exigir rendición de cuentas a quienes las discriminen o vulneren sus derechos. Asimismo, se espera que esta edición sirva como fuente de consulta a quienes impulsan cambios sustantivos contra la discriminación hacia las mujeres con iniciativas, políticas públicas y legislación que permitan a las mujeres el pleno goce de sus derechos (ONU, s.f.).

\section{PARTE II}

Artículo 7. Los Estados Partes tomarán todas las medidas apropiadas para eliminar la discriminación contra la mujer en la vida política y pública del país y, en particular, garantizando, en igualdad de condiciones con los hombres el derecho a: a) Votar en todas las elecciones y referéndums públicos y ser elegibles para todos los organismos cuyos miembros sean objeto de elecciones públicas;

b) Participar en la formulación de las políticas gubernamentales y en la ejecución de éstas, y ocupar cargos públicos y ejercer todas las funciones públicas en todos los planos gubernamentales; c) Participar en organizaciones y asociaciones no gubernamentales que se ocupen de la vida pública y política del país (ONU, s.f.).

Artículo 8. Los Estados Partes tomarán todas las medidas apropiadas para garantizar a la mujer, en igualdad de condiciones con el hombre y sin discriminación alguna, la oportunidad de representar a su gobierno en el plano internacional y de participar en la labor de las organizaciones internacionales. (ONU, s.f.).

\section{Marco Jurídico De Origen Internacional}


Derivado de los Tratados Internacionales, y como Estado miembro del Sistema Universal de Derechos Humanos de la ONU y del Sistema Interamericano de Derechos Humanos de la OEA, México ha suscrito un número importante de convenciones internacionales sobre derechos humanos de las mujeres, por lo que el estado mexicano necesariamente ha adoptado varios compromisos que han contribuido en buena medida al avance de la igualdad de género.

Como ya se mencionó, un referente fundamental en el establecimiento de las acciones afirmativas en la legislación mexicana, es la Convención para la Eliminación de Todas las Formas de Discriminación contra la Mujer (CEDAW), ratificada por México el 23 de marzo de 1981. (D.O.F. de 12 de mayo de 1981). Asimismo, la Convención Interamericana para Prevenir, Sancionar y Erradicar la Violencia contra la Mujer (Convención de Belém Do Pará), las cuales señalan que las mujeres tienen derecho al acceso igualitario a las funciones públicas de su país y a participar en los asuntos públicos, incluyendo la toma de decisiones. (Comisión Nacional para Prevenir y Erradicar la Violencia Contra las Mujeres, 2017).

\section{Leyes en México que abordan el tema de la equidad de género}

En la Constitución Política de los Estados Unidos Mexicanos, a partir de la reforma de junio de 2011, los derechos humanos reconocidos en los tratados internacionales de los que México forma parte, adquieren rango constitucional y, por tanto, no pueden ser contravenidos por disposiciones federales o estatales. Esta reforma obliga a realizar una interpretación progresiva y pro persona al analizar cualquier cuestión relacionada con los derechos humanos como es el caso de los derechos políticos de las mujeres. (Rodríguez, Erika (Coord), 2017).

Entre los principales artículos se encuentran:

El Artículo 1, a detalle enuncia en el Título Primero, Capítulo I, De los Derechos Humanos y sus Garantías, Denominación del Capítulo reformada en el Diario Oficial de la Federación, DOF, el 10 de junio de 2011:

Artículo $1^{\circ}$. En los Estados Unidos Mexicanos todas las personas gozarán de los derechos humanos reconocidos en esta constitución y en los tratados internacionales de los que el Estado Mexicano sea parte, así como de las garantías para su protección, cuyo ejercicio no podrá restringirse ni suspenderse salvo en los casos y bajo las condiciones que esta Constitución establece. Párrafo reformado en el Diario Oficial de la Federación, DOF, el 10 de junio de 2011. 
Las normas relativas a los derechos humanos se interpretarán de conformidad con esta Constitución y con los tratados internacionales de la materia favoreciendo en todo tiempo a las personas la protección más amplia. (Const., 2011).

El Artículo 41 contiene lo referente a la observación del principio de paridad de género en los distintos ámbitos, a detalle enuncia en el Título Segundo, Capítulo I, De la Soberanía Nacional y de la Forma de Gobierno:

Artículo 41. El pueblo ejerce su soberanía por medio de los Poderes de la Unión, en los casos de la competencia de éstos, y por los de los Estados y la Ciudad de México, en lo que toca a sus regímenes interiores, en los términos respectivamente establecidos por la presente Constitución Federal y las particulares de cada Estado y de la Ciudad de México, las que en ningún caso podrán contravenir las estipulaciones del Pacto Federal. Párrafo reformado en el Diario Oficial de la Federación, DOF, el 29 de enero de 2016.

La ley determinará las formas y modalidades que correspondan, para observar el principio de paridad de género en los nombramientos de las personas titulares de las secretarías de despacho del Poder Ejecutivo Federal y sus equivalentes en las entidades federativas. En la integración de los organismos autónomos se observará el mismo principio. Párrafo adicionado DOF 06-06-2019 (Const., 2019).

La Ley General Para La Igualdad Entre Mujeres y Hombres se publicó en el Diario Oficial de la Federación el 2 de agosto de 2006, su última reforma data del 14 de junio de 2018 y con respecto a la equidad de género establece, entre otras cosas, lo siguiente, en el Título I, Capítulo Primero, Disposiciones Generales:

Artículo 1. La presente Ley tiene por objeto regular y garantizar la igualdad de oportunidades y de trato entre mujeres y hombres, proponer los lineamientos y mecanismos institucionales que orienten a la Nación hacia el cumplimiento de la igualdad sustantiva en los ámbitos público y privado, promoviendo el empoderamiento de las mujeres y la lucha contra toda discriminación basada en el sexo. Sus disposiciones son de orden público e interés social y de observancia general en todo el Territorio Nacional. Art. reformado DOF 14-11-2013. 
Artículo 2. Son principios rectores de la presente Ley: la igualdad, la no discriminación, la equidad y todos aquellos contenidos en la Constitución Política de los Estados Unidos Mexicanos.

Artículo 3. Son sujetos de los derechos que establece esta Ley, las mujeres y los hombres que se encuentren en territorio nacional, que, por razón de su sexo, independientemente de su edad, estado civil, profesión, cultura, origen étnico o nacional, condición social, salud, religión, opinión o discapacidad, se encuentren con algún tipo de desventaja ante la violación del principio de igualdad que esta Ley tutela. Párrafo reformado DOF 16-06-2011.

Artículo 5. Para los efectos de esta Ley se entenderá por:

I. Acciones Afirmativas. Es el conjunto de medidas de carácter temporal correctivo, compensatorio y/o de promoción, encaminadas a acelerar la igualdad sustantiva entre mujeres y hombres; Fracción reformada DOF 14-11-2013.

II. Discriminación. Toda distinción, exclusión o restricción que, basada en el origen étnico o nacional, sexo, edad, discapacidad, condición social o económica, condiciones de salud, embarazo, lengua, religión, opiniones, preferencias sexuales, estado civil o cualquier otra, tenga por efecto impedir o anular el reconocimiento o el ejercicio de los derechos y la igualdad real de oportunidades de las personas; Fracción adicionada DOF 14-11-2013.

III. Discriminación contra la Mujer. Toda distinción, exclusión o restricción basada en el sexo que tenga por objeto o por resultado menoscabar o anular el reconocimiento, goce o ejercicio por la mujer, independientemente de su estado civil, sobre la base de la igualdad del hombre y la mujer, de los derechos humanos y las libertades fundamentales en las esferas política, económica, social, cultural y civil o en cualquier otra esfera; Fracción adicionada DOF 14-11-2013.

IV. Igualdad de Género. Situación en la cual mujeres y hombres acceden con las mismas posibilidades y oportunidades al uso, control y beneficio de bienes, servicios y recursos de la 
sociedad, así como a la toma de decisiones en todos los ámbitos de la vida social, económica, política, cultural y familiar; Fracción adicionada DOF 14-11-2013.

V. Igualdad Sustantiva. Es el acceso al mismo trato y oportunidades para el reconocimiento, goce o ejercicio de los derechos humanos y las libertades fundamentales; Fracción adicionada DOF 14-11-2013.

VI. Perspectiva de Género. Concepto que se refiere a la metodología y los mecanismos que permiten identificar, cuestionar y valorar la discriminación, desigualdad y exclusión de las mujeres, que se pretende justificar con base en las diferencias biológicas entre mujeres y hombres, así como las acciones que deben emprenderse para actuar sobre los factores de género y crear las condiciones de cambio que permitan avanzar en la construcción de la igualdad de género; Fracción adicionada DOF 14-11-2013.

VII. Transversalidad. Es el proceso que permite garantizar la incorporación de la perspectiva de género con el objetivo de valorar las implicaciones que tiene para las mujeres y los hombres cualquier acción que se programe, tratándose de legislación, políticas públicas, actividades administrativas, económicas y culturales en las instituciones públicas y privadas; Fracción reformada y recorrida DOF 14-11-2013.

VIII. Sistema Nacional. Sistema Nacional para la Igualdad entre Mujeres y Hombres, y Fracción reformada y recorrida DOF 14-11-2013.

IX. Programa Nacional. Programa Nacional para la Igualdad entre Mujeres y Hombres. Fracción reformada y recorrida DOF 14-11-2013.

Artículo 6. La igualdad entre mujeres y hombres implica la eliminación de toda forma de discriminación en cualquiera de los ámbitos de la vida, que se genere por pertenecer a cualquier sexo.

Capítulo Primero, De La Política Nacional En Materia De Igualdad: 
Artículo 17. La Política Nacional en Materia de Igualdad entre mujeres y hombres deberá establecer las acciones conducentes a lograr la igualdad sustantiva en el ámbito, económico, político, social y cultural.

La Política Nacional que desarrolle el Ejecutivo Federal deberá considerar los siguientes lineamientos:

I. Fomentar la igualdad entre mujeres y hombres en todos los ámbitos de la vida;

II. Asegurar que la planeación presupuestal incorpore la perspectiva de género, apoye la transversalidad y prevea el cumplimiento de los programas, proyectos y acciones para la igualdad entre mujeres y hombres;

III. Fomentar la participación y representación política equilibrada entre mujeres y hombres; Capítulo Tercero, De La Participación Y Representación Política Equilibrada De Las Mujeres Y Los Hombres:

Artículo 35. La Política Nacional propondrá los mecanismos de operación adecuados para la participación equitativa entre mujeres y hombres en la toma de decisiones políticas y socioeconómicas.

Artículo 36. Para los efectos de lo previsto en el artículo anterior, las autoridades correspondientes desarrollarán las siguientes acciones:

I. Favorecer el trabajo parlamentario con la perspectiva de género;

II. Garantizar que la educación en todos sus niveles se realice en el marco de la igualdad entre mujeres y hombres y se cree conciencia de la necesidad de eliminar toda forma de discriminación;

III. Evaluar por medio del área competente de la Comisión Nacional de los Derechos Humanos, la participación equilibrada entre mujeres y hombres en los cargos de elección popular;

IV. Promover participación y representación equilibrada entre mujeres y hombres dentro de las estructuras de los partidos políticos; 
V. Fomentar la participación equitativa de mujeres y hombres en altos cargos públicos;

VI. Desarrollar y actualizar estadísticas desagregadas por sexo, sobre puestos decisorios y cargos directivos en los sectores público, privado y de la sociedad civil, y

VII. Fomentar la participación equilibrada y sin discriminación de mujeres y hombres en los procesos de selección, contratación y ascensos en el servicio civil de carrera de los poderes Ejecutivo, Legislativo y Judicial (Ley General Para La Igualdad Entre Mujeres y Hombres, 2018).

En la Ley General de Instituciones y Procedimientos Electorales (LEGIPE), publicada en el Diario Oficial de la Federación el 23 de mayo de 2014, y con la última actualización al 27 de enero de 2017, se establece en el Libro Segundo, De la Integración de los Poderes Legislativo y Ejecutivo de la Unión y de las Entidades Federativas, así como de los Ayuntamientos, Título Primero, De la Participación de los Ciudadanos en las Elecciones, Capítulo I, De los Derechos y Obligaciones:

Artículo 7. 1) Votar en las elecciones constituye un derecho y una obligación que se ejerce para integrar órganos del Estado de elección popular. También es derecho de los Ciudadanos y obligación para los partidos políticos la igualdad de oportunidades y la paridad entre hombres y mujeres para tener acceso a cargos de elección popular (Ley General de Instituciones y Procedimientos Electorales, 2017).

La Ley General de Partidos Políticos, publicada en el Diario Oficial de la Federación el 23 de mayo de 2014, con la última reforma del 13 de agosto de 2015, estableció nuevas condiciones a favor de los derechos políticos de las mujeres para ser electas en los cargos de representación popular:

Artículo 3.

1. Los partidos políticos son entidades de interés público con personalidad jurídica y patrimonio propios, con registro legal ante el Instituto Nacional Electoral o ante los Organismos Públicos Locales, y tienen como fin promover la participación del pueblo en la vida democrática, 
contribuir a la integración de los órganos de representación política y, como organizaciones de ciudadanos, hacer posible el acceso de éstos al ejercicio del poder público.

2. Es derecho exclusivo de los ciudadanos mexicanos formar parte de partidos políticos y afiliarse libre e individualmente a ellos; por tanto, queda prohibida la intervención de:

a) Organizaciones civiles, sociales o gremiales, nacionales o extranjeras;

b) Organizaciones con objeto social diferente a la creación de partidos, y

c) Cualquier forma de afiliación corporativa.

3. Los partidos políticos promoverán los valores cívicos y la cultura democrática entre niñas, niños y adolescentes, y buscarán la participación efectiva de ambos géneros en la integración de sus órganos, así como en la postulación de candidatos.

4. Cada partido político determinará y hará públicos los criterios para garantizar la paridad de género en las candidaturas a legisladores federales y locales. Éstos deberán ser objetivos y asegurar condiciones de igualdad entre géneros.

5. En ningún caso se admitirán criterios que tengan como resultado que alguno de los géneros le sean asignados exclusivamente aquellos distritos en los que el partido haya obtenido los porcentajes de votación más bajos en el proceso electoral anterior (Ley General de Partidos Políticos, 2015).

La Ley Federal para Prevenir y Eliminar la Discriminación, publicada en el Diario Oficial de la Federación el 11 de junio de 2003, con la última reforma publicada el 21 de junio de 2018, con respecto a la participación política enuncia en el Capítulo II, Medidas Para Prevenir La Discriminación:

Artículo 9. (Se deroga el anterior párrafo primero y se recorren los demás en su orden) Párrafo derogado DOF 20-03-2014.

Con base en lo establecido en el artículo primero constitucional y el artículo 1, párrafo segundo, fracción III de esta Ley se consideran como discriminación, entre otras: 
VIII. Impedir la participación en condiciones equitativas en asociaciones civiles, políticas o de cualquier otra índole;

IX. Negar o condicionar el derecho de participación política y, específicamente, el derecho al sufragio activo o pasivo, la elegibilidad y el acceso a todos los cargos públicos, así como la participación en el desarrollo y ejecución de políticas y programas de gobierno, en los casos y bajo los términos que establezcan las disposiciones aplicables (Ley Federal para Prevenir y Eliminar la Discriminación, 2018).

La Ley de la Comisión Nacional de los Derechos Humanos, publicada en el Diario Oficial de la Federación el 29 de junio de 1992, con las últimas reformas publicadas el 25 de junio de 2018, establece, con respecto a la igualdad entre hombres y mujeres, lo siguiente:

DECRETO por el que se adiciona la Ley de la Comisión Nacional de los Derechos Humanos. Publicado en el Diario Oficial de la Federación el 26 de enero de 2006.

ARTÍCULO ÚNICO. - Se adiciona una fracción XIV Bis al artículo 6 de la Ley de la Comisión Nacional de los Derechos Humanos, para quedar como sigue: ...

\section{TRANSITORIOS}

PRIMERO. - El presente Decreto entrará en vigor al día siguiente de su publicación en el Diario Oficial de la Federación.

SEGUNDO. - La Comisión Nacional de los Derechos Humanos realizará las reformas o adiciones a su Reglamento Interior dentro de los sesenta días siguientes a la entrada en vigor del presente decreto, donde establecerá las funciones específicas del área encargada del seguimiento, evaluación y monitoreo en materia de igualdad entre mujeres y hombres; sin perjuicio de las adecuaciones que sean necesarias a la entrada en vigor de la Ley General de Igualdad entre Mujeres y Hombres.

TERCERO. - Las adecuaciones reglamentarias a que se refiere el artículo anterior y que al efecto realice la Comisión en el ámbito de su competencia, deberán contemplar medidas tendientes a capacitar y especializar a los servidores públicos a cargo del área encargada del seguimiento, evaluación y monitoreo en materia de igualdad entre mujeres y hombres (Ley de la Comisión Nacional de los Derechos Humanos, 2018). 
La Ley Del Instituto Nacional De Las Mujeres fue publicada en el Diario Oficial de la Federación el 12 de enero de 2001, con la última reforma publicada del 16 de febrero de 2018, establece en Capítulo I, Disposiciones Generales:

Artículo 1. Las disposiciones de esta Ley son de orden público y de observancia general en toda la República, en materia de igualdad de género e igualdad de derechos y oportunidades entre hombres y mujeres, en los términos del Artículo Cuarto, párrafo segundo de la Constitución Política de los Estados Unidos Mexicanos. Artículo reformado DOF 16-02-2018.

Artículo 4. El objeto general del Instituto es promover y fomentar las condiciones que posibiliten la no discriminación, la igualdad de oportunidades y de trato entre los géneros; el ejercicio pleno de todos los derechos de las mujeres y su participación igualitaria en la vida política, cultural, económica y social del país...

Artículo 7.- El Instituto tendrá las siguientes atribuciones:

I. Apoyar la formulación de políticas públicas gubernamentales e impulsar las de la sociedad, para alcanzar la igualdad de género; Fracción reformada DOF 16-02-2018

II. Impulsar la incorporación de la perspectiva de género en la planeación nacional del desarrollo, programación y presupuesto de egresos de la federación;

III. Estimular la incorporación de la perspectiva de género en las políticas públicas y en la elaboración de programas sectoriales o, en su caso, institucionales específicos, así como en las acciones de las dependencias y entidades de la Administración Pública Federal centralizada y paraestatal;

IV. Impulsar la incorporación de la perspectiva de género en el programa anual de cada Dependencia y Entidad de la Administración Pública Federal, centralizada y paraestatal, así como de los sectores en general vinculados con estos instrumentos, para la ejecución de sus programas sectoriales o, en su caso, institucionales específicos;

V. Procurar, impulsar y apoyar el ejercicio pleno de los derechos de las mujeres, así como el fortalecimiento de mecanismos administrativos para el mismo fin; 
VI. Proponer, en el marco del Plan Nacional de Desarrollo, el Programa Nacional para la Igualdad entre Mujeres y Hombres y, evaluar periódica y sistemáticamente la ejecución del mismo; Fracción reformada DOF 04-06-2015.

VII. Establecer y concertar acuerdos y convenios con las autoridades en los tres niveles de gobierno para promover, con la participación, en su caso, de los sectores social y privado, las políticas, acciones y programas que se establezcan en el Programa Nacional para la Igualdad entre Mujeres y Hombres; Fracción reformada DOF 04-06-2015 (Ley Del Instituto Nacional De Las Mujeres, 2018).

\section{Reformas a la Constitución Política de los Estados Unidos Mexicanos en el año 2019 en materia de paridad de género}

Sobre la paridad de género, el 06 de junio de 2019, se publicó en el Diario Oficial de la Federación el Decreto por el que se reforman los artículos 2, 4, 35, 41, 52, 53, 56, 94 y 115; de la Constitución Política de los Estados Unidos Mexicanos, en materia de Paridad entre Géneros.

ARTÍCULO ÚNICO. Se reforman: la fracción VII del apartado A del artículo 2; el párrafo primero del artículo 4; el párrafo primero y la fracción II del artículo 35; los párrafos primero y segundo de la fracción I del artículo 41; el artículo 52; los párrafos primero y segundo del artículo 53; los párrafos primero y segundo del artículo 56; el tercer párrafo del artículo 94; el párrafo primero de la fracción I del artículo 115. Se adicionan: un segundo párrafo, recorriéndose los subsecuentes al artículo 41; un párrafo octavo, recorriendo los subsecuentes, al artículo 94, todos de la Constitución Política de los Estados Unidos Mexicanos, para quedar como sigue:

Artículo $2^{\circ} \ldots$

A. ...

VII. Elegir, en los municipios con población indígena, representantes ante los ayuntamientos, observando el principio de paridad de género conforme a las normas aplicables...

B. ...

Artículo 4o.- La mujer y el hombre son iguales ante la ley. Ésta protegerá la organización y el desarrollo de la familia. 
Artículo 35. Son derechos de la ciudadanía:

II. Poder ser votada en condiciones de paridad para todos los cargos de elección popular, teniendo las calidades que establezca la ley. El derecho de solicitar el registro de candidatos y candidatas ante la autoridad electoral corresponde a los partidos políticos, así como a los ciudadanos y las ciudadanas que soliciten su registro de manera independiente y cumplan con los requisitos, condiciones y términos que determine la legislación;

III. ... a VIII. ...

Artículo 41....

La ley determinará las formas y modalidades que correspondan, para observar el principio de paridad de género en los nombramientos de las personas titulares de las secretarías de despacho del Poder Ejecutivo Federal y sus equivalentes en las entidades federativas. En la integración de los organismos autónomos se observará el mismo principio.

I. Los partidos políticos son entidades de interés público; la ley determinará las normas y requisitos para su registro legal, las formas específicas de su intervención en el proceso electoral y los derechos, obligaciones y prerrogativas que les corresponden. En la postulación de sus candidaturas, se observará el principio de paridad de género.

Los partidos políticos tienen como fin promover la participación del pueblo en la vida democrática, fomentar el principio de paridad de género, contribuir a la integración de los órganos de representación política, y como organizaciones ciudadanas, hacer posible su acceso al ejercicio del poder público, de acuerdo con los programas, principios e ideas que postulan y mediante el sufragio universal, libre, secreto y directo, así como con las reglas que marque la ley electoral para garantizar la paridad de género, en las candidaturas a los distintos cargos de elección popular. Sólo los ciudadanos y ciudadanas podrán formar partidos políticos y afiliarse libre e individualmente a ellos; por tanto, quedan prohibidas la intervención de organizaciones gremiales o con objeto social diferente en la creación de partidos y cualquier forma de afiliación corporativa.

II. ... a VI. ...

Artículo 52. La Cámara de Diputados estará integrada por 300 diputadas y diputados electos según el principio de votación mayoritaria relativa, mediante el sistema de distritos 
electorales uninominales, así como por 200 diputadas y diputados que serán electos según el principio de representación proporcional, mediante el Sistema de Listas Regionales, votadas en circunscripciones plurinominales.

Artículo 53. La demarcación territorial de los 300 distritos electorales uninominales será la que resulte de dividir la población total del país entre los distritos señalados. La distribución de los distritos electorales uninominales entre las entidades federativas se hará teniendo en cuenta el último censo general de población, sin que en ningún caso la representación de una entidad federativa pueda ser menor de dos diputados o diputadas de mayoría.

Para la elección de los 200 diputados y diputadas según el principio de representación proporcional y el Sistema de Listas Regionales, se constituirán cinco circunscripciones electorales plurinominales en el país conformadas de acuerdo con el principio de paridad, y encabezadas alternadamente entre mujeres y hombres cada periodo electivo. La Ley determinará la forma de establecer la demarcación territorial de estas circunscripciones.

Artículo 56. La Cámara de Senadores se integrará por ciento veintiocho senadoras y senadores, de los cuales, en cada Estado y en la Ciudad de México, dos serán elegidos según el principio de votación mayoritaria relativa y uno será asignado a la primera minoría. Para estos efectos, los partidos políticos deberán registrar una lista con dos fórmulas de candidatos. La senaduría de primera minoría le será asignada a la fórmula de candidaturas que encabece la lista del partido político que, por sí mismo, haya ocupado el segundo lugar en número de votos en la entidad de que se trate.

Las treinta y dos senadurías restantes serán elegidas según el principio de representación proporcional, mediante el sistema de listas votadas en una sola circunscripción plurinominal nacional, conformadas de acuerdo con el principio de paridad, y encabezadas alternadamente entre mujeres y hombres cada periodo electivo. La ley establecerá las reglas y fórmulas para estos efectos.

Artículo 94. ...

La Suprema Corte de Justicia de la Nación se compondrá de once integrantes, Ministras y Ministros, y funcionará en Pleno o en Salas.

La ley establecerá la forma y procedimientos mediante concursos abiertos para la integración de los órganos jurisdiccionales, observando el principio de paridad de género. 
Artículo 115....

I. Cada Municipio será gobernado por un Ayuntamiento de elección popular directa, integrado por un Presidente o Presidenta Municipal y el número de regidurías y sindicaturas que la ley determine, de conformidad con el principio de paridad. La competencia que esta Constitución otorga al gobierno municipal se ejercerá por el Ayuntamiento de manera exclusiva y no habrá autoridad intermedia alguna entre éste y el gobierno del Estado.

II. ... a X. ...

\section{TRANSITORIOS}

PRIMERO. - El presente Decreto entrará en vigor al día siguiente de su publicación en el Diario Oficial de la Federación.

SEGUNDO. - El Congreso de la Unión deberá, en un plazo improrrogable de un año a partir de la entrada en vigor del presente Decreto, realizar las adecuaciones normativas correspondientes a efecto de observar el principio de paridad de género establecido en esta Constitución, en los términos del segundo párrafo del artículo 41.

TERCERO. - La observancia del principio de paridad de género a que se refiere el artículo 41, será aplicable a quiénes tomen posesión de su encargo, a partir del proceso electoral federal o local siguiente a la entrada en vigor del presente Decreto, según corresponda.

Por lo que hace a las autoridades que no se renuevan mediante procesos electorales, su integración y designación habrá de realizarse de manera progresiva a partir de las nuevas designaciones y nombramientos que correspondan, de conformidad con la ley.

CUARTO. - Las legislaturas de las entidades federativas, en el ámbito de su competencia, deberán realizar las reformas correspondientes en su legislación, para procurar la observancia del principio de paridad de género en los términos del artículo 41 (Diario Oficial de la Federación, 2019).

\section{Resultados de las elecciones federales 2018 en México}

La LXIV Legislatura de la Cámara de Diputados, que tomó posesión el 1 de septiembre de 2018, está conformada por 241 mujeres, que representan el 48.2\%, y por 251 hombres, que equivalen al 51.8\%, y se le considera una de las legislaturas más equilibradas de la historia de dicho órgano depositario del Poder Legislativo Federal (Cámara de Diputados, s.f.). (Tabla 1) 


\begin{tabular}{|c|c|c|c|c|c|c|}
\hline \multicolumn{7}{|c|}{ Integración de la Cámara de Diputados por Género y Grupo Parlamentario } \\
\hline Grupo Parlamentario & Mujeres & $\%$ & Hombres & $\%$ & Total & $\%$ \\
\hline Movimiento Regeneración Nacional & 128 & $\begin{array}{c}49 . \\
8\end{array}$ & 129 & $\begin{array}{c}50 . \\
2\end{array}$ & 257 & $\begin{array}{c}51 . \\
4\end{array}$ \\
\hline Partido Acción Nacional & 33 & $\begin{array}{c}42 . \\
3\end{array}$ & 45 & $\begin{array}{c}57 . \\
7\end{array}$ & 78 & $\begin{array}{c}15 . \\
6\end{array}$ \\
\hline Partido Revolucionario Institucional & 21 & $\begin{array}{c}45 . \\
7\end{array}$ & 25 & $\begin{array}{c}54 . \\
3 \\
\end{array}$ & 46 & 9.2 \\
\hline Partido del Trabajo & 17 & $\begin{array}{c}47 . \\
2\end{array}$ & 19 & $\begin{array}{c}52 . \\
8\end{array}$ & 36 & 7.2 \\
\hline Movimiento Ciudadano & 15 & $\begin{array}{c}55 . \\
6\end{array}$ & 12 & $\begin{array}{c}44 . \\
4\end{array}$ & 27 & 5.4 \\
\hline Partido Encuentro Social & 14 & $\begin{array}{c}51 . \\
9\end{array}$ & 13 & $\begin{array}{c}48 . \\
1\end{array}$ & 27 & 5.4 \\
\hline Partido Verde Ecologista de México & 4 & $\begin{array}{c}30 . \\
8\end{array}$ & 9 & $\begin{array}{c}69 . \\
2 \\
\end{array}$ & 13 & 2.6 \\
\hline Partido de la Revolución Democrática & 8 & $\begin{array}{c}72 . \\
7\end{array}$ & 3 & $\begin{array}{c}27 . \\
3\end{array}$ & 11 & 2.2 \\
\hline Sin Partido & 1 & 20 & 4 & 80 & 5 & 1 \\
\hline TOTAL & 241 & $\begin{array}{c}48 . \\
2\end{array}$ & 259 & $\begin{array}{c}51 . \\
8\end{array}$ & 500 & 100 \\
\hline
\end{tabular}

Tabla1. Elaboración propia.

Fuente: Cámara de Diputados. (marzo 2020)

En el Senado de la República, la LXIV Legislatura está compuesta por 63 mujeres, que representan el $49.21 \%$, y por 65 hombres que representan el $50.78 \%$ del total, siendo también una de las más equitativas en cuanto a la representación por género (Senado de la República, s.f.). (Tabla 2)

\begin{tabular}{|c|c|c|c|c|c|c|}
\hline \multicolumn{7}{|c|}{ Integración de la Cámara de Senadores por Género y Grupo Parlamentario } \\
\hline Grupo Parlamentario & Mujeres & $\%$ & Hombres & $\%$ & Total & $\%$ \\
\hline Movimiento Regeneración Nacional & 28 & $\begin{array}{c}44.4 \\
4\end{array}$ & 32 & $\begin{array}{c}49.2 \\
3\end{array}$ & 60 & $\begin{array}{c}46.8 \\
7\end{array}$ \\
\hline Partido Acción Nacional & 13 & $\begin{array}{c}20.6 \\
3\end{array}$ & 11 & $\begin{array}{c}16.9 \\
2\end{array}$ & 24 & $\begin{array}{c}18.7 \\
5\end{array}$ \\
\hline Partido Revolucionario Institucional & 7 & $\begin{array}{c}11.1 \\
1\end{array}$ & 7 & $\begin{array}{c}10.7 \\
6\end{array}$ & 14 & $\begin{array}{c}10.9 \\
3\end{array}$ \\
\hline Partido del Trabajo & 4 & 6.34 & 2 & 3.07 & 6 & 4.68 \\
\hline Movimiento Ciudadano & 3 & 4.71 & 6 & 9.23 & 9 & 7.03 \\
\hline Partido Encuentro Social & 4 & 6.34 & 0 & 0 & 4 & 3.12 \\
\hline Partido Verde Ecologista de México & 4 & 6.34 & 3 & 4.61 & 7 & 5.46 \\
\hline
\end{tabular}




\begin{tabular}{|c|c|c|c|c|c|c|}
\hline Partido de la Revolución Democrática & 0 & 0 & 3 & 4.61 & 3 & 2.34 \\
\hline Sin Grupo Parlamentario & 0 & 0 & 1 & 1.53 & 1 & 0.8 \\
\hline TOTAL & 63 & $\begin{array}{c}49.2 \\
1\end{array}$ & 65 & $\begin{array}{c}50.7 \\
8\end{array}$ & 128 & 100 \\
\hline
\end{tabular}

Tabla 2. Elaboración propia.

Fuente: Senado de la República. (marzo 2020)

En resumen, como resultado de las elecciones del 2018, las mujeres ocupan 241 de las 500 curules en San Lázaro y 63 de los 128 escaños en la Cámara Alta.

Es relevante el hecho de que las mujeres ocupen tan significativo porcentaje, muy cercano al $50 \%$ en ambas cámaras, ya que esto refleja una mayor participación política como género y permite la posibilidad de impulsar agendas legislativas a favor de la igualdad de género y la erradicación de la violencia contra las mujeres. Cabe señalar que la paridad que hoy en día se puede apreciar es histórica y se debe mayormente a las medidas implementadas por el Instituto Nacional Electoral (INE) a través de las cuotas de género.

\section{Dictámenes históricos en 2019-2020 sobre la paridad de género en el Senado de la República}

\section{Aprueban paridad sustantiva en todos los espacios de toma de decisiones del Estado}

En mayo de 2019, como una reforma profunda que cambiará las reglas para beneficio de las mujeres, por unanimidad, el Senado aprobó en lo general y lo particular el dictamen que reforma diversos artículos de la Constitución Política en materia de paridad de género, a fin de garantizar el pleno ejercicio de los derechos políticos de las mujeres en México, con la paridad sustantiva en todos los espacios de toma de decisiones del Estado.

La reforma avalada con 120 votos consagra el derecho de las mujeres a participar en todos los espacios políticos en condiciones de igualdad con los hombres. Para ello, establece la obligatoriedad constitucional de observar dicho principio en la integración de los Poderes de la Unión. Incluye el mismo esquema para los estados, así como para la integración de los ayuntamientos; es decir, paridad en los tres poderes de todas las entidades federativas y los municipios.

Se establece que la Suprema Corte de Justicia estará integrada por ministras y ministros. La conformación de los órganos jurisdiccionales se realizará mediante concursos abiertos, con igual número de mujeres que de hombres, en los procesos para esos efectos. En los artículos 
transitorios se señala que las legislaturas de las entidades federativas deberán realizar reformas en su legislación para garantizar los procedimientos de elección, designación y nombramiento de sus autoridades, bajo el principio de paridad. De la misma manera, la paridad de género se aplicará para los partidos políticos, órganos autónomos y en cualquier entidad, órgano u organismo que ejerza funciones de autoridad en el ámbito de la Federación, las entidades federativas, municipios y alcaldías de la Ciudad de México. Sus autoridades deberán ser electas, nombradas o designadas, según corresponda, respetando el principio de paridad de género. La modificación constitucional también incluye dicho principio en la elección de representantes ante los ayuntamientos en los municipios con población indígena.

La reforma se alcanzó con un acuerdo histórico que se construyó con la pluralidad de las fuerzas políticas que conforman el Senado de la República e incorpora el principio constitucional de paridad de género como eje rector para la integración de todos los órganos del Estado mexicano. En el artículo 41 de la Constitución se propone observar dicho principio en los nombramientos de las personas titulares de las secretarías de despacho del Poder Ejecutivo Federal y sus equivalentes en las entidades federativas, así como en la integración de los órganos autónomos.

Adicionalmente, para la postulación de sus candidaturas, se obliga a los partidos políticos a observar este precepto constitucional en las candidaturas al Poder Legislativo Federal y a los demás cargos de elección popular. En tanto, el artículo 94 mandata que la ley que regule la organización y funcionamiento del Poder Judicial de la Federación incorpore la paridad de género para la integración de los órganos jurisdiccionales federales.

A partir de la aprobación de este dictamen es necesario implementar políticas públicas, medidas y acciones que aseguren a todas las mujeres su participación política, con libertad, seguridad y las garantías de que no vivirán violencia. Con la reforma se abandona el sistema de cuotas y entramos a la era paritaria de este país, porque este principio no debe reconocerse y garantizarse con base en "sentenciazos". (Senado de la República, s.f.).

\section{Aprueba Senado paridad en organismos del Estado}

En marzo de 2020, y de acuerdo a los objetivos de la Agenda 2030, respecto a la igualdad y empoderamiento de las mujeres, con 86 votos a favor, el Senado de la República aprobó 
modificaciones a diversas leyes para que los consejos, comités, asambleas consultivas y diversos organismos y entidades públicos se conformen de manera paritaria.

En caso de que los órganos estén conformados por un número non se conformará de forma alterna, con ello se elimina la brecha de desigualdad entre mujeres y hombres, y se asegura la participación plena de las mujeres en los espacios de discusión y toma de decisiones.

Dichas modificaciones se apegan a los objetivos de la Agenda 2030 porque establece la igualdad de género y el empoderamiento de mujeres y niñas, vela por su participación plena, efectiva y la igualdad de oportunidades en todos los niveles de decisiones en la vida pública, política y económica.

Con las enmiendas aprobadas este día, el Estado mexicano garantiza la contribución activa de las mujeres en la vida pública del país para consolidar la democracia, ya que la sociedad exige la inclusión y participación de todas las personas que la conforman.

Con ello, se busca aumentar el número de mujeres en los espacios de representación política y de toma de decisiones, pero también pretende un impulso cualitativo, a fin de profundizar procesos más democráticos en el ámbito de la política.

La presidente de la Comisión Para la Igualdad de Género, senadora Martha Lucía Micher Camarena, aseguró que la paridad es un compromiso de todas y todos, ya que solo con unidad se lograrán los resultados y consolidar la democracia en el país.

El dictamen reforma y adiciona diversas disposiciones de la Ley General de Transparencia y Acceso a la Información Pública, la Ley General de Instituciones y Procedimientos Electorales, la Ley General del Sistema Nacional Anticorrupción, y la Ley General de Partidos Políticos.

Así como de la Ley Federal de Competencia Económica, la Ley Federal de Telecomunicaciones y Radiodifusión, la Ley del Banco de México, la Ley de la Comisión Nacional de los Derechos Humanos, la Ley Orgánica de la Fiscalía General de la República y la Ley de los Órganos Reguladores Coordinadores en materia Energética.

\section{Establecen lenguaje que prioriza la paridad de género}

El Pleno del Senado aprobó por 82 votos, un dictamen que modifica 31 leyes, con el propósito de establecer un lenguaje que garantice la paridad de género en el marco jurídico del 
país y así abrir paso a una nueva visión política que abone a la erradicación de la violencia de género.

El documento precisa que, a pesar de los avances legislativos, la paridad no ha significado que las legisladoras y legisladores participen de manera igualitaria en la toma de decisiones, puesto que hay instituciones de gobierno que siguen teniendo mayor presencia masculina.

Al respecto, la senadora del PAN, Gloria Elizabeth Núñez Sánchez dijo que las reformas buscan mejorar el acceso al poder de las mujeres, apostando por una legislación que cumpla con el principio de paridad, sin importar los colores. "Las mujeres en el Senado de la república estamos juntas y daremos ejemplo de una verdadera sororidad".

El dictamen fue enviado a la Cámara de Diputados para sus efectos constitucionales.

Posteriormente, las y los senadores avalaron por 79 votos, otro dictamen que reforma nueve leyes, a efecto de armonizarlas y así garantizar que el principio de igualdad sustantiva se traduzca en un mandato para la participación paritaria en aquellos espacios donde persisten desigualdades entre hombres y mujeres.

A través de las reformas se busca consolidar el principio de paridad en las asambleas consultivas, comités, consejos y las titularidades y puestos de toma de decisión.

El dictamen fue enviado a la Cámara de Diputados para sus efectos constitucionales (Senado de la República, s.f.).

\section{Conclusiones}

A lo largo de la historia en México, las mujeres han jugado un papel protagónico en las grandes transformaciones políticas del país y, sin embargo, han sido excluidas de la toma de decisiones y relegadas del ámbito público y está claro ahora que no puede haber una sociedad democrática si persiste la desigualdad y la discriminación de la mujer. Se puede concluir que, como país, se ha ido avanzando en la lucha por la protección de los derechos de las mujeres y aunque dicho avance ha sido de manera gradual, con ello se han ido sentando bases sólidas para poder contar con leyes que defiendan los derechos de la mujer a través de la equidad y la paridad de género y, por lo tanto, se les reconozca y se les brinde igualdad de oportunidades a las mujeres con respecto a los hombres. 
Cabe señalar que una de las herramientas más efectivas para lograr la equidad definitivamente han sido las cuotas de género, que buscan garantizar la integración de las mujeres a la política y producir un cambio cultural para evitar el predominio de un solo género en la representación política, ya que se ha visto que persisten diferencias numéricas de presencia femenina con respecto a la masculina en aquellos sistemas en donde las cuotas de género no se contemplan. Y aunque las cuotas parecen ser condición necesaria, no son suficientes para impulsar la real participación política femenina y su presencia en las altas esferas de la política y el gobierno.

Es innegable también, que lo logrado hasta el momento en México para reconocer los derechos de las mujeres se debe entre otras cosas a la voluntad política y al consenso de todos los partidos políticos. Con los dictámenes recientes que fomentan la paridad de género, inicia una nueva etapa en la vida pública del país, se trata de reformas profundas, que garantizan la paridad de género y la igualdad sustantiva en los poderes de la Unión, a nivel federal, estatal y municipal, así como en los órganos constitucionales autónomos, y son reformas que pasarán a formar parte de los grandes logros de la historia del feminismo mexicano, ya que permitirán alcanzar un mayor equilibrio en la representación política y a partir de ello, las reglas cambiarán sustancialmente en beneficio de las mujeres, ya que se evitará que las mujeres sean invisibilizadas, excluidas y utilizadas, sólo para adornar el discurso de la igualdad, como ocurrió por muchos años.

En México, con lo anteriormente mencionado, se siguen dando pasos en una dirección correcta para alcanzar una sociedad más igualitaria y lograr que la participación de las mujeres sea plena e igualitaria, avanzando así en el ejercicio de la ciudadanía y la plena realización de los derechos humanos.

Sin embargo, se tiene que continuar trabajando en el tema para seguir derrumbando las barreras que han obstaculizado y limitado la participación de la mujer como lo son los estigmas, los estereotipos, la violencia en todas sus formas, el machismo, la misoginia y la discriminación, que aún se presentan de manera recurrente en nuestro país en todos los ámbitos.

Los partidos políticos siguen siendo los que controlan el acceso y el avance de las mujeres en las estructuras de poder político y para ser consideradas, deben ascender dentro de la estructura de los mismos, ya que estos tienen la capacidad de nominar los candidatos a cargos públicos e históricamente se han caracterizado por ser estructuras sexistas que no incorporaban a sus filas a las mujeres en igualdad de condiciones que, a los varones, impidiéndoles el acceso a puestos de 
dirigencia y a su estructura. Actualmente, con lo que se ha trabajado al respecto, aparte de promover la paridad de género en sus candidaturas y destinar el 3\% de su gasto ordinario para capacitación a mujeres, deben de tomar muy en serio este compromiso, promoviendo que se les impartan cursos de liderazgo, tienen que fortalecer liderazgos de las mujeres elegidas, deben implementar capacitaciones permanentes y obligatorias tanto para hombres como para mujeres sobre la sensibilización de género, así como el contemplar que en sus estatutos figure de manera real la igualdad de género en todos sus órganos.

Sin duda, al analizar nuestra historia como país sobre el tema podemos observar algo muy importante, que, si bien no estamos en las mismas circunstancias restrictivas de antes, tampoco estamos aún a donde debemos llegar, es decir, a vivir en una sociedad que reconozca el valor y las capacidades de la persona más allá de su género, comprendiendo que la verdadera equidad se dará al eliminar la lucha entre hombres y mujeres, mediante la educación de las futuras generaciones, para que la visión de género no imponga una mirada femenina, sino complemente la masculina, y con este cambio, el país sea bien gobernado por hombres y mujeres, ya que no se trata únicamente de cubrir una cuota mayor de cargos políticos a favor de las mujeres, sino de reconocer, respetar y garantizar la participación equilibrada de mujeres y hombres en la toma de decisiones, y la promoción de la igualdad de oportunidades.

\section{PROGRESS ON EQUITY AND GENDER PARITY IN MEXICO}

\section{Abstract}

This article analyzes the advances on gender equity and parity in Mexico through the reforms that have been made to legislation and international organizations, observing the impact of gender quotas, and the effect that these factors have had in the political participation of women, which historically has been presented with a disadvantage with respect to men. The results of the 2018 federal election and the positions held by women derived from said democratic exercise will be analyzed, which, as an effect of gender quotas, have changed the course of representation both in the Chamber of Deputies and in the Senate of the Republic. The results of the investigation allow us to observe that, in Mexico, it has been possible to see an evolution for almost 25 years on the subject, to go from having up to $70 \%$ of legislators of the same gender in 1996, to count, as a result of the mandatory gender parity in the 2018 election, with $49.2 \%$ of women in the Senate of the Republic and $48.2 \%$ in the Chamber of Deputies, considered today as historical figures.

Keywords: Gender equality, women, politics, gender parity, Mexico. 


\section{Bibliografía}

1. (s.f.).

2. Cámara de Diputados del H. Congreso de la Unión. (2015, 13 de agosto). Ley General de Partidos Políticos. Diario Oficial de la Federación. Recuperado el 26 de 03 de 2020, de http://www.diputados.gob.mx/LeyesBiblio/pdf/LGPP_130815.pdf

3. Cámara de Diputados del H. Congreso de la Unión. (2017, 27 de enero). Ley General de Instituciones y Procedimientos Electorales . Diario Oficial de la Federación. Recuperado el 26 de 03 de 2020, de http://www.diputados.gob.mx/LeyesBiblio/pdf/LGIPE_270117.pdf

4. Cámara de Diputados del H. Congreso de la Unión. (2018, 16 de febrero). Ley Del Instituto Nacional De Las Mujeres . Diario Oficial de la Federación. Recuperado el 27 de 03 de 2020, de http://www.diputados.gob.mx/LeyesBiblio/pdf/88_160218.pdf

5. Cámara de Diputados del H. Congreso de la Unión. (2018, 21 de junio). Ley Federal para Prevenir y Eliminar la Discriminación. Diario Oficial de la Federación.

Recuperado el 26 de 03 de 2020, de http://www.diputados.gob.mx/LeyesBiblio/pdf/262_210618.pdf

6. Cámara de Diputados del H. Congreso de la Unión. (2018, 25 de junio). Ley de la Comisión Nacional de los Derechos Humanos. Diario Oficial de la Federación. Recuperado el 26 de 03 de 2020, de http://www.diputados.gob.mx/LeyesBiblio/pdf/47_250618.pdf

7. Cámara de Diputados del H. Congreso de la Unión. (2018,14 de junio). Ley General Para La Igualdad Entre Mujeres y Hombres. Diario Oficial de la Federación.

Recuperado el 25 de 03 de 2020, de http://www.diputados.gob.mx/LeyesBiblio/ref/lgimh.htm

8. Cámara de Diputados. (s.f.). www.diputados.gob.mx. Recuperado el 25 de 03 de 2020, de http://sitl.diputados.gob.mx/LXIV_leg/cuadro_genero.php

9. CÁMARA DE DIPUTADOS. (s.f.).www.diputados.gob.mx. (C. C. Género, Ed.) Recuperado el 29 de 03 de 2020, de http://www.diputados.gob.mx/documentos/Comite_CEAMEG/Libro_Part_Pol.pdf

10. Cámara de Diputados y Senado de la República. (s.f.). www.diputados.gob.mx. Recuperado el 29 de 03 de 2020, de www.senado.gob.mx.

11. CEPAL. (2004). Obtenido de 9 CEPAL. Caminos hacia la Equidad de Género en América Latina y El Caribe. $9^{a}$ Conferencia Regional de la Mujer en: www.eclac.cl

12. Chile, B. d. (s.f.). Recuperado el 25 de 03 de 2020, de Biblioteca del Congreso Nacional de Chile:

https://www.bcn.cl/obtienearchivo?id=repositorio/10221/20239/4/equidad\%20de\%20ge nero_\%20final_v2.pdf 
13. Comisión Nacional para Prevenir y Erradicar la Violencia Contra las Mujeres. (2017). www.gob.mx. Recuperado el 07 de 04 de 2020

14. Constitución Política de los Estados Unidos Mexicanos (Const.). (2011, junio 10). Artículo 1. H. Congreso de la Unión LXIV Legislatura.

15. Constitución Política de los Estados Unidos Mexicanos [Const.]. (2019, 06 de junio). Artículo 41. H. Congreso de la Unión LXIV Legislatura. Recuperado el 26 de 03 de 2020, de http://www.diputados.gob.mx/LeyesBiblio/pdf/1_060320.pdf

16. DIARIO OFICIAL DE LA FEDERACIÓN. (2019, 06 de junio). Diario Oficial de la Federación. Recuperado el 26 de 03 de 2020, de https://www.dof.gob.mx/nota_detalle.php?codigo $=5562178 \&$ fecha $=06 / 06 / 2019$

17. Fernández, A. M. (2011). scielo.org.mx. Recuperado el 27 de 03 de 2020, de http://www.scielo.org.mx/scieloOrg/php/reference.php?pid=S018757952011000200010\&caller=www.scielo.org.mx\&lang=es

18. Fraser, N. (1997). Iustitia Interrupta. Reflexiones críticas desde la posición "postsocialista". Colombia: Siglo del Hombre Editores. Universidad de los Andes.

19. Medina, A. (2010). La participación política de las mujeres. De las cuotas de género a la paridad. México: Centro de Estudios para el Adelanto de las Mujeres y la Equidad de Género. H. Congreso de la Unión. Cámara de Diputados. LXI Legislatura .

20. Mora, L. (2006). Igualdad Y Equidad De Género: Aproximación Teórico-Conceptual Herramientas De Trabajo En Género Para Oficinas Y Contrapartes Del Unfpa. UNFPA. Obtenido de https://www.bcn.cl/obtienearchivo?id=repositorio/10221/20239/4/equidad\%20de $\% 20 \mathrm{ge}$ nero_\%20final_v2.pdf

21. OMS. (2002). Obtenido de Política de la OMS en materia de género. Integración de las perspectivas de género en la labor de la OMS.: www.who.int/gender/docum ents/en /sppolicy.pdf

22. ONU. (s.f.). UNWOMEN.ORG. Recuperado el 25 de 03 de 2020, de https://www2.unwomen.org/$/$ media/field\%20office\%20mexico/documentos/publicaciones/2011/convenci\%C3\%B3 n\%20pdf.pdf?la=es

23. Rodríguez, Erika (Coord). (2017). www.diputados.gob.mx. (C. d. Diputados, Editor) Recuperado el 07 de 04 de 2020, de http://biblioteca.diputados.gob.mx/janium/bv/ce/lxiii/leg_persgen_lxiii.pdf

24. Senado de la República. (s.f.). www.senado.gob.mx. Recuperado el 25 de 03 de 2020, de https://www.senado.gob.mx/64/senadores/integracion

25. Senado de la República. (s.f.). www.senado.gob.mx. Recuperado el 27 de 03 de 2020, de http://comunicacion.senado.gob.mx/index.php/informacion/boletines/44832- 
aprueban-por-unanimidad-paridad-sustantiva-en-todos-los-espacios-de-toma-dedecisiones-del-estado.html

26. Senado de la República. (s.f.). www.senado.gob.mx. Recuperado el 27 de 03 de 2020, de http://comunicacion.senado.gob.mx/index.php/informacion/boletines/47848aprueba-senado-paridad-en-organismos-del-estado.html

27. Solorio, R. (junio de 2014). www.diputados.gob.mx. (CEDIP, Editor) Recuperado el 27 de 03 de 2020, de

http://www5.diputados.gob.mx/index.php/esl/content/download/17912/90078/file/Parid adgenero.pdf

28. UNESCO. (s.f.). Gender equity. Recuperado el 25 de 03 de 2020

Trabalho enviado em 08 de abril de 2020

Aceito em 19 de maio de 2020 